\title{
An Ecological Study on Edwardsiella tarda in Flounder Farms
}

\author{
M. Mamnur Rashid, Kazumitsu Honda, Toshihiro Nakai \\ and Kiyokuni Muroga* \\ Faculty of Applied Biological Science, Hiroshima University, \\ Kagamiyama, Higashi-Hiroshima 724, Japan
}

(Received June 16, 1994)

\begin{abstract}
An ecological investigation on Edwardsiella tarda was carried out in two Japanese flounder (Paralichthys olivaceus) farms in Fukuyama City from April to December 1992. E. tarda was isolated from $86 \%$ of water, $44 \%$ of sediment and $14 \%$ of fish samples in one pond, and $22 \%$ of water, $0 \%$ of sediment and $2 \%$ of fish samples in the other pond, although epizootics caused by $E$. tarda were not observed in either pond. Serological studies proved that all the isolates of $E$. tarda from flounder and its environment shared a common heat stable O-antigen. Almost all the isolates tested exhibited pathogenicity to flounder by intramuscular injection. In survivability tests of selected isolates in sea water and freshwater, they perished within 7 days in sea water but survived longer period in freshwater.

These results suggest that there is only one serotype of $E$. tarda which has pathogenicity to flounder in the environment of flounder farms.
\end{abstract}

Edwardsiella tarda has been known to be pathogenic for a wide variety of animals including several species of fishes (Austin and Austin, 1993). In Japan, the disease (edwardsiellosis) caused by this pathogen constitutes an economical threat particularly in eel culture in freshwater (Hoshina, 1962; Wakabayashi and Egusa, 1973a, b) and flounder culture in sea water (Yasunaga et al., 1982; Nakatsugawa, 1983; Kodama et al., 1987).

Ecological studies on this pathogen in eel culture ponds were made (Minagawa et al., 1983; Park et al., 1983) and E. tarda was detected from healthy eels and their culture environment. Distribution of the pathogen in a flounder farm was also studied (Kanai et al., 1988), but the pathogen was not detected from flounder culture environment except for the period when edwardsiellosis prevailed.

In the present work, an ecological survey of the pathogen in apparently healthy flounder (Paralichthys olivaceus) and their culture environment was made. Physiological, serological and pathological characteristics of isolated $E$. tarda were also studied.

\footnotetext{
* Author to whom correspondence should be addressed.
}

\section{Materials and Methods}

\section{Field sampling}

Monthly samplings were done in two flounder farms (Pond A and Pond B) in Fukuyama City, Hiroshima Prefecture, from April through December 1992. In both farms, fish were reared in land based ponds throughout that period. Fish (10 fish), pond waters, supply waters (sand-filtered coastal sea water), sediments and foods for the fish were sampled from each farm. Fish were carried to the laboratory in Hiroshima University (HigashiHiroshima City) in oxygen-filled plastic bags or in ice boxes spending 2 or $3 \mathrm{~h}$. Water, mud and food samples were also carried in ice boxes.

\section{Bacterial isolation}

Fish: At the first sampling in April, when average body weight of fish was $0.1 \mathrm{~g}$, fish were homogenized individually with $2 \mathrm{ml}$ of sterilized physiological saline $(0.85 \% \mathrm{NaCl}$ : PS). A $0.1 \mathrm{~m} l$ of each original homogenate, 10- and 100-fold dilutions with PS were inoculated in duplicate onto Salmonella-Shigella (SS) agar (Eiken) for colony count (direct plating culture). From the second sampling in May, with larger fish, the above method was continued for the intestine samples instead of the whole body. In 
addition, $1 \mathrm{ml}$ of the intestine, liver, spleen, and kidney homogenates (sample:PS=1:2) was put into $10 \mathrm{ml}$ double-strength SS broth (DSSS) as a selective enrichment medium for $E$. tarda (Wyatt et al., 1979) (enrichment culture).

Water: Waters, undiluted, $10-$ and 100 -fold diluted, were inoculated onto SS agar for colony count. One $\mathrm{ml}$ of undiluted water samples were subjected to enrichment culture with DSSS. From the third sampling in June, each water sample of $100 \mathrm{~m} l$ was passed through a membrane filter $(0.45 \mu \mathrm{m}$, Millipore) and that filter was subjected to enrichment culture.

Sediment and food: Direct plating and enrichment culture were done for sediment samples and only enrichment culture was performed for foods (pelleted artificial feed).

Post-incubation works: Inoculated SS agar were incubated at $25^{\circ} \mathrm{C}$ for 2 days and $E$. tarda-like colonies were selected by their characteristic appearance, transparent colonies with black center. For selective enrichment culture, after 2 days of incubation in DSSS at $25^{\circ} \mathrm{C}$, one loopful of each culture was streaked onto SS agar, followed by incubation for 2 days at the same temperature. E. tarda-like colonies were again streaked onto SS agar to obtain pure culture, and stocked in $1 / 3$ strength heart infusion (HI) agar (Eiken) for further examinations.

\section{Characterization of isolates}

Morphological and biochemical characteristics: Rapid identification of the isolated bacteria was performed using triple sugar iron (TSI), sulfide-indolemotility (SIM), lysine, and mannitol test media, and ONPG disks, as suggested by Minagawa et al. (1983). Final identification of presumptive $E$. tarda isolates was done based on detailed morphological and biochemical characterization. All biochemical tests were performed at $25^{\circ} \mathrm{C}$ unless otherwise specified.

Serological analysis: Bacteria were cultured on nutrient agar (NA, Eiken) at $25^{\circ} \mathrm{C}$ for $48 \mathrm{~h}$. Slide agglutination tests for isolated $E$. tarda were carried out with 10- and 20-fold diluted rabbit serum which was raised against $E$. tarda NUF251, a reference strain isolated from diseased flounder in Nagasaki Prefecture. The agglutination titers of anti-NUF251 serum were measured in micro-titer plates using both formalin-killed (formalin 0.3\%) and heat-killed $\left(100^{\circ} \mathrm{C}, 2.5 \mathrm{~h}\right)$ cells. In addition to NUF251, E22 which was isolated from diseased eel and classified to serotype A (Park et al., 1983) was also used as a reference strain.

Pathogenicity test: Selected 16 isolates of $E$. tarda were tested on their pathogenicity. E. tarda NUF251 was used as a positive control. A 2-day-culture of each isolate on NA at $25^{\circ} \mathrm{C}$ was diluted in sterilized PS to a concentration of $10^{5}-10^{6} \mathrm{CFU} / \mathrm{ml}$. Five flounder (average body weight: $13.1 \mathrm{~g}$ ) were injected intramuscularly with $0.05 \mathrm{~m} l$ of each bacterial suspension or of PS as a control group. No food was given during the experiment. The fish were observed everyday for 15 days at about $22^{\circ} \mathrm{C}$ of water temperature and dead fish were submitted to bacterial isolation with NA and SS agar from kidney.

\section{Survival of E. tarda in waters}

Two isolates from water and healthy fish were selected to study their survivabilities in sea water, freshwater (from a freshwater pond in the campus of Hiroshima University), and distilled water. Two reference strains (NUF251 and E22) were also used for this study. One hundred $\mathrm{ml}$ of each kind of water were autoclaved and kept at $20^{\circ} \mathrm{C}$ overnight. Two day-culture of 4 strains at $25^{\circ} \mathrm{C}$ on NA was diluted in PS to make a concentration of $10^{7} \mathrm{CFU} / \mathrm{ml}$, and $0.1 \mathrm{~m} l$ of the suspension was inoculated into each of the water media. The inoculated water were kept at $20^{\circ} \mathrm{C}$ and viable count was made on NA at appropriate intervals. Slide agglutination tests were performed using anti-E. tarda NUF251 rabbit serum to confirm that the grown colonies are of $E$. tarda.

\section{Results}

\section{Ecological survey}

Water temperature and fish body weight at each sampling are shown in Table 1. The growth rate of fish of pond A was much higher than that of pond B.

There were no apparent outbreaks of $E$. tarda infection in the two farms investigated during the study period. Results of $E$. tarda detection by direct plating (DP) and enrichment culture (EC) methods are shown in Table 2 and 3, respectively. EC method gave a much higher detection rate than DP method and filter paper method was highly effective for the detection of $E$. tarda from waters. By EC method (Table 3), E. tarda was detected from pond water (filter paper method) and/or sediment samples from June to September, and from July the pathogen was 
Table 1. Water temperature and fish body weight at each sampling in two flounder farms

\begin{tabular}{|c|c|c|c|c|}
\hline \multirow{2}{*}{ Date (1992) } & \multicolumn{2}{|c|}{ Water temperature $\left({ }^{\circ} \mathrm{C}\right)$} & \multicolumn{2}{|c|}{ Mean fish body weight ${ }^{1)}(\mathrm{g})$} \\
\hline & Pond A & Pond B & Pond A & Pond B \\
\hline Apr. 30 & 19.5 & 16.3 & 0.1 & 0.1 \\
\hline May 27 & 19.5 & 17.2 & 2.1 & 2.0 \\
\hline Jun. 30 & 20.2 & 19.5 & 14.7 & 13.6 \\
\hline Jul. 28 & 23.5 & 24.2 & 42.2 & 34.9 \\
\hline Aug. 31 & 27.4 & 27.1 & 97.9 & 61.7 \\
\hline Sep. 28 & 22.4 & 22.8 & 140.5 & 96.6 \\
\hline Oct. 30 & 21.5 & 21.2 & 196.0 & 137.2 \\
\hline Nov. 26 & 15.9 & 15.0 & 247.3 & 143.9 \\
\hline Dec. 22 & 13.5 & 13.2 & 273.1 & 160.7 \\
\hline
\end{tabular}

1) Average body weight of 10 fish.

Table 2. Results of E. tarda detection by direct plating method from apparently healthy flounder and their culture environment in two flounder farms

\begin{tabular}{|c|c|c|c|c|c|c|c|c|c|}
\hline \multirow{2}{*}{$\begin{array}{l}\text { Materials for } \\
\text { isolation }\end{array}$} & \multicolumn{9}{|c|}{ Detection of $E$. tarda } \\
\hline & Apr. 30 & May 27 & Jun. 30 & Jul. 28 & Aug. 31 & Sep. 28 & Oct. 30 & Nov. 26 & Dec. 22 \\
\hline Pond water & $-\mid-1)$ & $-1-$ & $-1-$ & $-1-$ & $-1-$ & $-1-$ & $-1-$ & $-1-$ & $-1-$ \\
\hline Supply water & $-1-$ & $-1-$ & $-1-$ & $-1-$ & $-1-$ & $-1-$ & $-1-$ & $-1-$ & $-1-$ \\
\hline Sediment & $-1-$ & $-1-$ & $-1-$ & $+1-$ & $-1-$ & $-1-$ & $-1-$ & $-1-$ & $+1-$ \\
\hline Fish & & & & & & & & & \\
\hline $\begin{array}{l}\text { whole body } \\
\text { intestine }\end{array}$ & $\begin{array}{l}-1- \\
\mathrm{ND}^{2)}\end{array}$ & $-1-$ & $-1-$ & $-1-$ & $+(1)^{3)} /-$ & $-1-$ & $+(1) /+(1)$ & $-1-$ & $+(1) /-$ \\
\hline
\end{tabular}

${ }^{1)}$ Results in A pond (A farm)/B pond (B farm); ${ }^{2)}$ Not done; ${ }^{3)}$ Number of fish from which $E$. tarda was isolated.

Table 3. Results of $E$. tarda detection by enrichment culture method from apparently healthy flounder and their culture environment in two flounder farms

\begin{tabular}{|c|c|c|c|c|c|c|c|c|c|}
\hline \multirow{2}{*}{$\begin{array}{l}\text { Materials for } \\
\text { isolation }\end{array}$} & \multicolumn{9}{|c|}{ Detection of $E$. tarda } \\
\hline & Apr. 30 & May 27 & Jun. 30 & Jul. 28 & Aug. 31 & Sep. 28 & Oct. 30 & Nov. 26 & Dec. 22 \\
\hline Pond water $1^{1)}$ & $\mathrm{ND}^{3)}$ & ND & $-(-4)$ & $-1-$ & $-1-$ & $-1-$ & $-1-$ & $-1-$ & $-1-$ \\
\hline $2^{2)}$ & ND & ND & $+1-$ & $+1+$ & $+1+$ & $+1-$ & $-1-$ & $+1-$ & $+1-$ \\
\hline Supply water 1 & ND & ND & $-1-$ & $-1-$ & $-1-$ & $-1-$ & $-1-$ & $-1-$ & $-1-$ \\
\hline 2 & ND & ND & $-1-$ & $+1-$ & $-1-$ & $+1-$ & $-1-$ & $-1-$ & $-1-$ \\
\hline Sediment & $-1-$ & $-1-$ & $+1-$ & $+1-$ & $-1-$ & $-1-$ & $+1-$ & $-1-$ & $+1-$ \\
\hline Food & $-1-$ & $-1-$ & $-1-$ & $-1-$ & $-1-$ & $-1-$ & $-1-$ & $-1-$ & $-1-$ \\
\hline \multicolumn{10}{|l|}{ Fish } \\
\hline whole body & $-1-$ & & & & & & & & \\
\hline intestine & ND & $-1-$ & $-1-$ & $-/+(1)^{5)}$ & $+(1) /-$ & $-1-$ & $+(2) /-$ & $+(3) /-$ & $+(4) /-$ \\
\hline liver & ND & $-1-$ & $-1-$ & $-1-$ & $+(1) /-$ & $-1-$ & $+(1) /-$ & $-1-$ & $+(1) /-$ \\
\hline spleen & ND & $-1-$ & $-1-$ & $-1-$ & $-1-$ & $-1-$ & $+(1) /-$ & $-1-$ & $+(1) /-$ \\
\hline kidney & ND & $-1-$ & $-1-$ & $-1-$ & $-1-$ & $-1-$ & $+(1) /-$ & $-1-$ & $+(1) /-$ \\
\hline
\end{tabular}

1) Enrichment culture of $1 \mathrm{~m} l$ water sample; ${ }^{2)}$ Enrichment culture of filter paper passed with $100 \mathrm{~m} l$ water sample; ${ }^{3)}$ Not done; ${ }^{4}$ Results in A pond (A farm)/B pond (B farm); ${ }^{5)}$ Number of fish from which $E$. tarda was isolated. 
Table 4. Characteristics of 28 isolates of $E$. tarda obtained in this study with those of $E$. tarda reported by Ewing et al. (1965)

\begin{tabular}{|c|c|c|c|c|c|}
\hline Characteristics & Present isolates & Ewing et al. & Characteristics & Present isolates & Ewing et al. \\
\hline Gram stain & - & - & Acid and gas from glucose & + & + \\
\hline Motility & + & + & Acid from: & & \\
\hline Oxidase & - & - & arabinose & - & - \\
\hline Catalase & + & + & cellobiose & - & - \\
\hline OF test & $F^{1)}$ & $\mathbf{F}$ & galactose & + & + \\
\hline Nitrate reduction & + & + & mannitol & - & - \\
\hline Gelatin liquefaction & - & - & mannose & + & + \\
\hline Indole & + & + & sucrose & - & - \\
\hline $\mathrm{H}_{2} \mathrm{~S}$ & + & + & Growth in $\mathrm{NaCl}$ : & & \\
\hline MR & + & + & $0 \%$ & + & $\mathrm{ND}^{3)}$ \\
\hline VP & - & - & $0.5 \%$ & + & ND \\
\hline$\beta$-galactosidase (ONPG) & - & - & $3 \%$ & + & ND \\
\hline Arginine decomposition & - & - & $6 \%$ & - & ND \\
\hline Lysine decarboxylation & + & + & Growth at: & & \\
\hline Ornithine decarboxylation & + & + & $4^{\circ} \mathrm{C}$ & - & ND \\
\hline Citrate utilization & $+(60 \%)^{2)}$ & - & $40^{\circ} \mathrm{C}$ & + & ND \\
\hline
\end{tabular}

${ }^{1)}$ F: Fermentative; ${ }^{2)}$ Percentage of strains showing positive result; ${ }^{3)}$ No data.

also detected from fish except September. Based on EC method, E. tarda detection rates from pond water (filter paper method), sediment and fish samples in pond A and B were $86 \%(6 / 7), 44 \%(4 / 9)$, $16 \%$ (14/90); and 29\% (2/7), 0\% (0/9), 2\% (2/90), respectively. Food samples were found to be free from $E$. tarda contamination in either farm.

Number of viable cells of $E$. tarda detected by DP method was from 8 to $62 \mathrm{CFU} / \mathrm{g}$ in fish intestine, and 5 to $420 \mathrm{CFU} / \mathrm{g}$ in sediment.

\section{Characteristics of isolates}

Morphological and biochemical characteristics: In total 40 isolates were picked up based on the colony appearance on SS agar plates, out of which 28 isolates were identified as $E$. tarda by rapid identification; 8 from pond water, 2 from supply water, 4 from sediment, 11 from intestine, 1 from liver, 1

Table 5. Agglutination titers of anti-E. tarda NUF251 rabbit serum against the present 28 isolates and two reference strains of $E$. tarda

\begin{tabular}{|c|c|c|}
\hline \multirow[b]{2}{*}{ Strain } & \multicolumn{2}{|c|}{ Titer } \\
\hline & $\begin{array}{l}\text { Formalin- } \\
\text { killed cell }\end{array}$ & $\begin{array}{c}\text { Heat- } \\
\text { killed cell }\end{array}$ \\
\hline Present 28 isolates & $320-1280$ & $80-320$ \\
\hline Reference strains: NUF251 & 1280 & 320 \\
\hline E22 & 320 & 160 \\
\hline
\end{tabular}

from spleen and 1 from kidney of flounder. All these 28 isolates were confirmed to be $E$. tarda by detailed characterization. Morphological and biochemical characteristics of the isolates are shown in Table 4. All results coincided with those of $E$. tarda reported by Ewing et al. (1965) except citrate utilization.

Serology: All the 28 isolates reacted positively in slide agglutination tests with 10- and 20-fold dilutions of anti-E. tarda NUF251 rabbit serum. Distribution of agglutination titers of antiserum against formalin-killed and heat-killed cells of the present 28 isolates and 2 reference strains (NUF251, E22) are shown in Table 5. In most of the isolates, the titer was 160 for heat-killed cells and 320 or 640 for formalin-killed cells.

Pathogenicity: Results of pathogenicity test are shown in Table 6. Except one intestinal isolate (AFI 10-7), all the isolates examined were proved to be highly virulent in flounder (mortality 80 or $100 \%$ within 6-8 days). Kidney samples of all dead fish showed growth of pure $E$. tarda colonies.

\section{Survivability in waters}

Results of survivability tests of the two present isolates (APW 08, AFK 12) (Table 6) and two reference strains (NUF251, E22) are shown in Fig. 1. The 4 strains survived for the entire 35 days of experimental period in freshwater (pond water) and for 14 to 21 days in distilled water, but in sea water, 
Table 6. Pathogenicity to Japanese flounder of the present 16 isolates and NUF251 (reference strain) of $E$. tarda

\begin{tabular}{|c|c|c|c|c|c|}
\hline \multirow{2}{*}{ Strain } & \multicolumn{3}{|c|}{ Source } & \multirow{2}{*}{$\begin{array}{l}\text { Dose CFU/fish } \\
\quad\left(\times 10^{4}\right)\end{array}$} & \multirow{2}{*}{$\begin{array}{c}\text { Mortality }{ }^{1)} \\
(\%)\end{array}$} \\
\hline & Pond & Date & Sample & & \\
\hline APW 06 & $\mathbf{A}$ & Jun. & Pond water & 4.0 & 100 \\
\hline BPS 06 & B & Jun. & Sediment & 7.0 & 100 \\
\hline ASW 07 & A & Jul. & Supply water & 4.0 & 80 \\
\hline BPW 07 & B & Jul. & Pond water & 7.0 & 100 \\
\hline APW 08 & A & Aug. & Pond water & 5.5 & 100 \\
\hline AFI 08 & A & Aug. & Fish intestine & 3.3 & 100 \\
\hline AFL 08 & A & Aug. & Fish liver & 11.0 & 100 \\
\hline APW 09 & $\mathbf{A}$ & Sep. & Pond water & 6.5 & 80 \\
\hline AFI 10-7 & $\mathbf{A}$ & Oct. & Fish intestine & 5.5 & 0 \\
\hline AFS 10 & A & Oct. & Fish spleen & 7.5 & 100 \\
\hline APS 10 & A & Oct. & Sediment & 10.0 & 100 \\
\hline BFI 10 & B & Oct. & Fish intestine & 4.3 & 100 \\
\hline AFI $12-5$ & A & Dec. & Fish intestine & 7.5 & 100 \\
\hline AFK 12 & A & Dec. & Fish kidney & 4.2 & 100 \\
\hline APW 12 & A & Dec. & Pond water & 7.0 & 100 \\
\hline APS 12 & $\mathbf{A}$ & Dec. & Sediment & 8.0 & 100 \\
\hline NUF251 & & & & 1.3 & 100 \\
\hline \multicolumn{4}{|c|}{ Control (Physiological saline) } & & 0 \\
\hline
\end{tabular}

1) Five fish were injected intramuscularly with each strain at $22^{\circ} \mathrm{C}$.
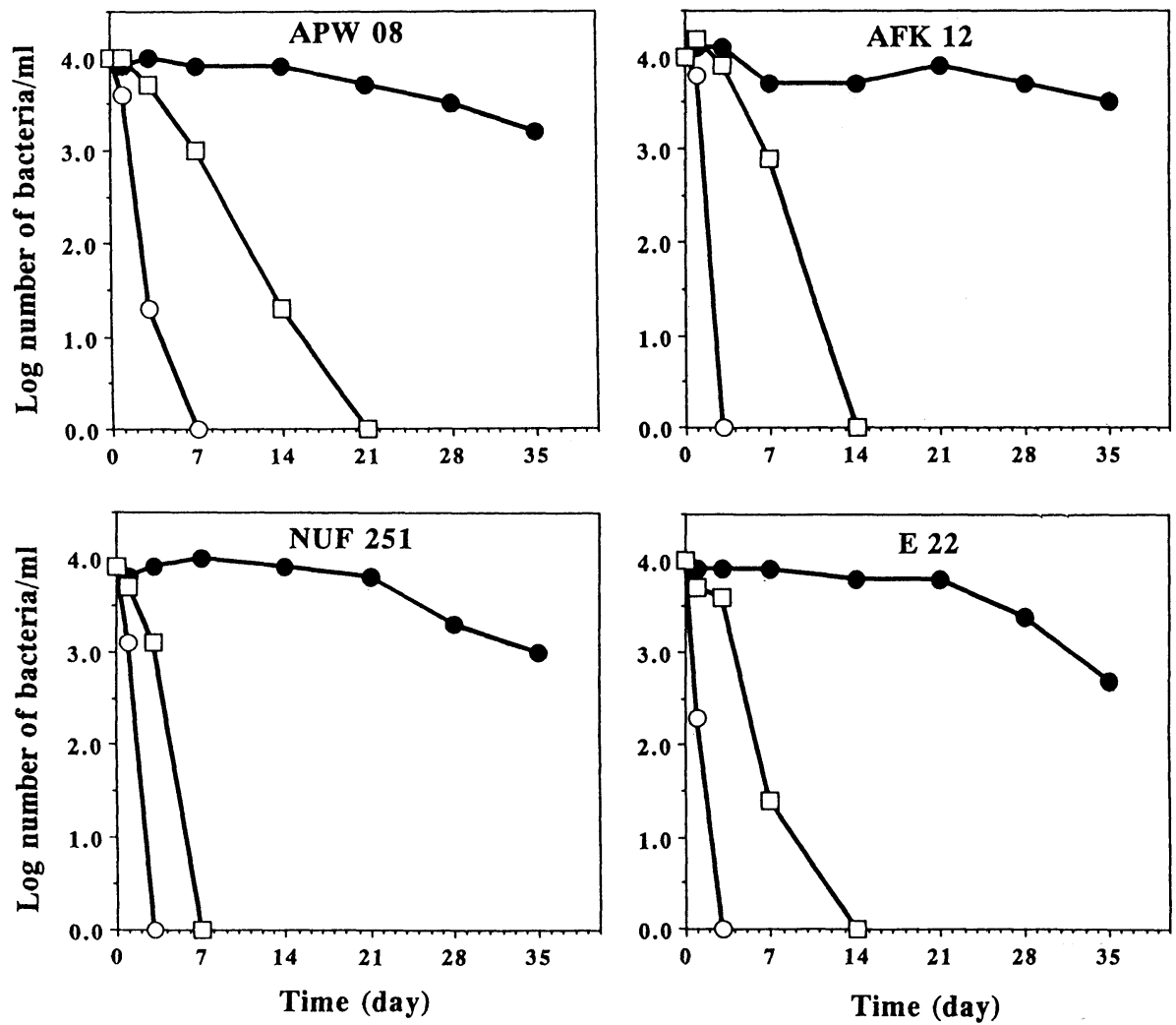

Fig. 1. Survival of the present 2 isolates and reference 2 strains of $E$. tarda in 3 different waters at $20^{\circ} \mathrm{C}$. $-\bigcirc-$ Sea water, 
they perished within 3 to 7 days.

\section{Discussion}

During the 9 months' sampling from April to December 1992, E. tarda was isolated first from the water or sediment samples in June. In July, it was also detected from the supply water and fish. Food was found to be free from $E$. tarda contamination throughout the survey. This finding may indicate that the original source of $E$. tarda was sea water in these two farms. These two farms suffered from edwardsiellosis in the previous year, thus the pathogen may have survived in sea water environments, probably in biotic elements, of coastal area where the used water from the farms are drained.

$E$. tarda was detected from the intestine most often with highest density among the tested organs. This seems to indicate that the intestine is the primary organ for the bacterial settlement in flounder as also reported by Kanai et al. (1988). Kanai et al. (1988) detected the pathogen from kidney only when its number in the intestines rose higher than $10^{3}$ CFU/g. But in the present work E. tarda was detected from the liver, spleen and kidney even when density of the pathogen in the intestine was lower than $10^{3} \mathrm{CFU} / \mathrm{g}$. This will imply that the pathogen may multiply simultaneously in several organs in certain cases of the infection.

The present study confirmed that $E$. tarda existed in environment of flounder even when the disease did not occur. Kanai et al. (1988) could not detect $E$. tarda from flounder culture environment except for one sampling made during an outbreak of the disease, though they also used enrichment culture technique. This difference seems to be due to the difference in flounder culture system between our sampling farms and their sampling farms: that is, our study was made in land based ponds and their study was made in net cages in sea water.

There were no great differences in the reaction against the antiserum in heat-killed states, indicating that all the isolates belong to one O-serotype. All the isolates examined except one was virulent to Japanese flounder. Park et al. (1983) and Minagawa et al. (1983) reported that there were some different serotypes among $E$. tarda strains isolated from healthy eels and their environment. Their isolates included avirulent or low virulent strains. On the contrary, E. tarda isolated from flounder and their environment consisted of homogeneous isolates in serological and pathological features not only in our study but also in the study made by Kanai et al. (1988). Also Mamnur Rashid et al. (1994) examined 28 strains of $E$. tarda isolated from diseased founder in different Prefectures of Japan and found that they also belong to one O-serotype which is identical to type A of eel strains. Therefore it is proved that $E$. tarda isolates either from diseased or healthy flounder or their environment belong to one O-serotype (type A of eel strains). This will imply that only some strains, either having pathogenicity or affinity for flounder and belonging to one serotype, could have existed in sea water environment. Therefore, the ecology of $E$. tarda in flounder farms is different from that of $E$. tarda in eel farms.

$E$. tarda is frequently isolated from cold-blooded animals and their environment, particularly freshwater (Farmer III and McWhorter, 1984). All the strains tested here died within a week in sea water, indicating that they can not live long in sea water itself. Thus, as mentioned above, only pathogenic strains have been able to remain in flounder or other animals in or around culture environment, although various types of the bacterium could have opportunity to enter into marine environment.

\section{Acknowledgements}

We thank Mr. Jun Kaneda and Mr. Masatoki Matsuki for facilitating samplings. The first author is grateful to the Monbusho for scholarship support.

\section{References}

Austin, B. and D. A. Austin (1993): Enterobacteriaceae representatives. In "Bacterial fish pathogens: Disease in farmed and wild fish", 2nd ed., Ellis Horwood Ltd., Chichester, pp. 188-226.

Ewing, W. H., A. C. McWhorter, M. R. Escobar and A. H. Lubin (1965): Edwardsiella, a new genus of Enterobacteriaceae based on a new species, $E$. tarda. Int. Bull. Bacteriol. Nomencl. Taxon., 15, 33-38.

Farmer III, J. J. and A. C. McWhorter (1984): Genus X. Edwardsiella Ewing and McWhorter 1965. In "Bergey's manual of systematic bacteriology, Vol. 1" (ed. by N. R. Krieg). Williams and Wilkins, Baltimore, pp. 486-491.

Hoshina, T. (1962): Studies on red disease of eels. $J$. Tokyo Univ. Fish., Spec. Rep., 6, 1-104. (In Japanese)

Kanai, K., S. Tawaki and Y. Uchida (1988): An ecological study of Edwardsiella tarda in flounder farm. Fish 
Pathol., 23, 41-47.

Kodama, H., T. Murai, Y. Nakanishi, F. Yamamoto, T. Mikami and H. Izawa (1987): Bacterial infection which produces high mortality in cultured Japanese flounder (Paralichthys olivaceus) in Hokkaido. Jpn. J. Vet. Res., 35, 227-234.

Mamnur Rashid, M., T. Mekuchi, T. Nakai and K. Muroga (1994): A serological study on Edwardsiella tarda strains isolated from diseased Japanese flounder (Paralichthys olivaceus). Fish Pathol., 29, 277.

Minagawa, T., T. Nakai and K. Muroga (1983): Edwardsiella tarda in eel culture environment. Fish Pathol., 17, 243-250.

Nakatsugawa, T. (1983): Edwardsiella tarda isolated from cultured young flounder. Fish Pathol., 18, 99-101.

Park, S.-I., H. Wakabayashi and Y. Watanabe (1983):
Serotype and virulence of Edwardsiella tarda isolated from eel and their environment. Fish Pathol., 18, 85-89.

Wakabayashi, H. and S. Egusa (1973a): Seasonal changes of bacterial infections among pond-cultured eels (Anguilla japonica). Fish Pathol., 8, 91-97.

Wakabayashi, H. and S. Egusa (1973b): Edwardsiella tarda (Paracolobactrum anguillimortiferum) associated with pond-cultured eel disease. Nippon Suisan Gakkaishi, 39, 931-936.

Wyatt, L. E., R. Nickelson II and C. Vanderzant (1979): Edwardsiella tarda in freshwater catfish and their environment. Appl. Environ. Microbiol., 38, 710-714.

Yasunaga, N., S. Ogawa and K. Hatai (1982): Characteristics of the fish pathogen Edwardsiella isolated from several species of cultured marine fishes. Bull. Nagasaki Prefect. Ins. Fish., 8, 57-65. (In Japanese) 